\title{
The Condemned Body Leaving the Courtroom
}

On 23 May 1754 a Scottish soldier named Ewen MacDonald was quartered at Newcastle. He spent his off-duty time drinking at a popular public house. By nightfall he was drunk and disorderly. What happened next was to make medico-legal history. In an inebriated state MacDonald started to brawl with some pub regulars. There was a physical altercation that spilled into the street and then into an alleyway. The soldier drew a knife in what he would later claim was self-defence. Lunging out he stabbed a local cooper called Robert Parker, piercing the jugular vein in the victim's neck. The drunken violence then escalated out of control. MacDonald was surrounded by a crowd of angry men threatening him with revenge. Cornered into two brick walls, he assaulted one of his attackers by breaking his arm and verbally abused the others. In the interim, the earlier injured party was forsaken in the affray and bled to death on the ground. By the early hours of the morning the Newcastle coroner was called to the fatal scene and at first light an 'inquest returned a verdict of wilful murder'. ${ }^{1}$ As a servingsolider, MacDonald should have been arrested by the military authorities but the Murder Act $(1752,25$ George II, c. 37) had recently come into force in Newcastle. Local magistrates decreed that the military suspect for being so violent must be imprisoned in the Borough gaol. A homicide charge would be held over to be tried at the next Assizes, leaving six weeks to determine the medical evidence and collate its findings with witness statements. By Michaelmas, there was considerable newspaper interest in

E.T. Hurren, Dissecting the Criminal Corpse, Palgrave

Historical Studies in the Criminal Corpse and its Afterlife, DOI 10.1057/978-1-137-58249-2_1 
the pending murder trial, and whether, if found guilty, a public dissection at Newcastle Surgeon's Hall would be ordered by the presiding judge. If so, it would be one of the first official cases of post-mortem punishment to take place in the Northern counties of Georgian England.

MacDonald was duly found guilty on 28 September 1754 . The judge passed the death sentence under the Murder Act: 'You will be hung by the neck until dead, and thence to be dissected and anatomized'. An extensive report of the execution and its post-mortem rituals appeared in the Newcastle General Magazine:

Ewen MacDonald was executed on the town moor, Newcastle pursuant to his sentence at the Assizes....this most unfortunate young man, who was only nineteen years of age appeared all the time of his confinement deeply effected with a true sense of guilt...but at the gallows his behaviour in endeavouring to throw the executioner from off the ladder was unbecoming to one just on the brink of eternity...His body was taken to Surgeon's Hall and there dissected. ${ }^{2}$

The following day, popular broadsheets also featured an execution-day special. They reported that the dissection of MacDonald was a troublesome affair for the Newcastle officials:

It was said that after the body was taken to Surgeon's Hall and placed ready for dissection, that the surgeons were called to a case at the Infirmary, who, on their return, found MacDonald so far recovered as to be sitting up; he immediately begged for mercy, but a young surgeon not wishing to be disappointed of the dissection, seized a wooden mallet with which he deprived him of life. ${ }^{3}$

The story of Half-hanged MacDonald featured prominently in the national and regional press coverage of the Murder Act. Yet, its medical controversy has been neglected in eighteenth-century crime studies. To the authorities in Newcastle a bungled execution seemed to undermine the deterrence objective of the new legislation. Newspaper editors questioned the medical circumstances of capital death given their obvious shortcomings. There was much speculation in the press about the force of the prisoner's willpower. Maybe he had a dangerous inner strength different to ordinary people that could defy the executioner. Some commentators thought that it was possible that the soldier had not been guilty of homicide but manslaughter; had God intervened to save his life? If so, it seemed 
immoral for divine justice to be confounded by surgeons determined to obtain a criminal corpse to dissect. Regional broadsheets carried detailed accounts from witnesses at the crime scene. These claimed that not only was MacDonald provoked into a bar fight but that exonerating evidence had been dismissed in court. The local forces of law and order meantime maintained that resentment against the Murder Act was running so high that the resuscitation story had been fabricated to sell more newspapers. Puzzlement was also expressed when the Local Record of Newcastle said shortly afterwards: 'It was further reported, as the just vengeance of God that this young man [penal surgeon] was soon after killed in the stable by his own horse. They used to show a mallet at Surgeon's Hall as the identical one used by the surgeon' to hasten death. ${ }^{4}$ Here then was a dramatic storyline that had engendered conflicting accounts, unsettling emotions, and unresolved controversy concerning the punishment of the condemned. In every respect this vignette encapsulates the key themes of this book.

\section{'RECULER POUR MIEUX SAUTER': STEPPING BACK, To SET ForTH}

Across a broad spectrum of early modern histories the criminal corpse has become an iconic cultural symbol and political standard-bearer for customary notions of law and order. ${ }^{6}$ The legal nemesis of the condemned has been intertwined with religious beliefs that were shaped by theologies of dying, death, and the afterlife. ${ }^{7}$ Hence the executed criminal was an integral feature of state power and its punishment rituals. ${ }^{8}$ It had a close association with the broad impulse of a 'scientific revolution' by 1700 . Over the next century, extensive newspaper coverage, pamphlet literature and popular street ballads, featuring executions were connected in the popular imagination to medical professionalization and Enlightenment values across Europe. ${ }^{9}$ Human anatomy teaching thus became essential for a European medical education, with Paris, Edinburgh and London (in that order of priority) attracting fee-paying students anxious to obtain extra qualifications as physicians and surgeons from dissecting criminal corpses. ${ }^{10}$ By the mid-Georgian period the general thrust of these intellectual trends was epitomised by the Murder $\mathrm{Act}^{11}$ and this is why it has stimulated extensive historical debate about its judicial authority, discretionary powers, and geographical coverage in England. ${ }^{12}$ There remains however a significant lacunae in our historical appreciation of the central role that the 
condemned body played in the public performance of the capital code's punishment schemata from the gallows to the grave. In our opening story, if the soldier's condemned body had not been traced onwards to its dissection, then the medico-legal controversy of Half-hanged MacDonald would be half-finished at best or more likely left out altogether of eighteenthcentury crime studies. The latter is common in the majority of cases that feature in criminal histories for Georgian England. That tends to limit our historical appreciation of a whole range of complex questions concerned with the moral authority of the capital code from its anti-mortem to postmortem outcomes. ${ }^{13}$ Before beginning therefore to revisit that punishment choreography in its entirety, this introduction sets out the generic themes that the next six chapters will be exploring to provide an overview of this book's novel approach.

A central and unifying feature of the chapters that follow is to revisit how exactly medico-legal officials knew that someone was dead at a time when timing death with limited medical equipment was still a scientific mystery in early modern England. It was a physical fact that basic biology shaped the legal remit of the new capital legislation. Executioners and penal surgeons had to work with the bodily limits of metabolism, physiology, and organ vitality, whether on the gallows or on arrival at dissection venues. Attempts were made to resolve these logistical medical issues by employing experienced executioners. The hangman's technology was altered with the change-over from a short to a long-drop, and tying the rope more securely with a trefoil rather than overhand knot. Even so, particular modes of execution, their medical competency, and mutable nature, remained obscure. It is noteworthy then that the majority of criminal historians have been reluctant to do in-depth studies of spatial execution sites or punishment spaces, and the diversity of medical opinions about the boundaries of life and death that informed/misinformed medico-legal officials. ${ }^{14}$ Steve Poole has recently pointed out that the introduction of a 'long-drop' was not efficient or humane with 'old and 'new' practices often running in parallel in provincial and metropolitan life. The rituals of procession were accordingly maintained up to the 1830s. These reflected ongoing concern about how to put to death the condemned in a humane fashion. It remains then a defining feature of eighteenth century crime histories that the corpse has often been left beneath the hanging-tree looking dead, but not truly dead, in the way that contemporaries understood those difficult medical definitions. It was well-known that outward appearances could be deceptive, especially in 
cold weather when the condemned body went into extreme-hypothermia. The historical literature, by abridging post-execution rites, has created a mistaken impression that penal surgeons only handled dead bodies from the gallows and that capital penalties from a medical standpoint were straightforward once a criminal stopped jerking on the hangman's rope. This book upends such medico-legal clichés in crime studies.

Few historians have traced the fascinating transitional language that expressed a great deal of contemporary concern about whether or not the condemned could survive capital death, or not, and what their capacity for pain was and therefore how powerful the criminal justice system could claim to be. In medico-legal circles there was a confusing vocabulary in vogue: the 'half-hanged', 'dead-alive', 'in the name of death', 'truly dead, or pained', 'death, the uncertain, certainty' and so on. This imaginative discourse was a reflection of shifting ideas about how biologically-speaking it was possible to be stuck in-between an earthly and spiritual world in early modern times. Mystical beliefs and their mutability gave rise to openended debates about how to time physical punishments. It was these logistical issues that had to be stage-managed by penal surgeons as well. They were required to double-check the biological status of the executed on arrival at a dissection location. If the criminal displayed any life-signs, however faint, then the surgeon had an ethical quandary. They could break the Hippocratic Oath or practice the new art of resuscitation in vogue from the 1780s. Some took the decision that it was more merciful to commit human vivisection with the lancet when brain function appeared to have failed and could not be measured with medical instruments. Others questioned whether the judicial authority of the courts gave them a special medical prerogative to experiment with the boundaries of life and death. This could be done to improve the quality of life for the law-abiding by testing the limits of death's dominion on murderers found guilty that were less than human. Yet, everything about this penal set-up exuded moral complexity. It placed a high degree of discretionary justice in the hands of surgeons, to such an extent, that some were uncomfortable with the level of personal culpability and responsibility. Hitherto these basic procedural pains and their ethical worries have seldom been reappraised in the historical literature. Hence rediscovered archival sources, reflecting a rich multiplicity, feature prominently in this book's reconstruction of process and participation on the punishment journeys of the condemned from the gallows to the grave between the Murder Act (1752) and the Anatomy Act (1832) in England. 
The widespread observation that contemporaries were often confused by the organic instability of death and dying, leads us to a second generic theme in this book. Many histories of crime and justice take the reader up to the critical point when the executed stopped jerking physically on the eighteenth century gallows. They then cite the admirable research of Vic Gatrell and Peter Linebaugh who some two decades ago traced strong reactions by ordinary people who protested about post-execution rites at the hanging-tree. ${ }^{15}$ Stories about how the crowd did confound the medico-legal officials by preventing bodies being handed over to surgeons are now well-known for some symbolic execution sites in central London. In the 1730s at Tyburn there were unedifying scenes when a number of surgeons fought each other, as well as the mob, for exclusive rights to the criminal corpse. ${ }^{16}$ These research findings have convinced leading crime and cultural historians that a Northern European sensibility emphasising body-integrity in death held sway in the popular imagination for those living in early modern England, especially once the Murder Act became law. ${ }^{17}$ The difficulty with these cultural perspectives is that, as Jonathan Sawday observes, capital punishment by dissection 'enjoyed' but only ever had a 'quasi-legal status' in England. ${ }^{18}$ The London Company of Barbers and Surgeons, as well as Oxford and Cambridge universities, obtained bodies according to customary rights laid out in a succession of Royal Charters. These crucially were endorsed by, but did not originate with, Parliament. Riots at Tyburn in the 1730s are then a classic example of how a moral economy seemed to inform the actions of the angry mob. It does not necessarily follow on that the same depth of feeling was held in provincial England, or that the same levels of antagonism were prevalent in a political economy two decades later when the Murder Act reached the statute books. Standard historical views, oft repeated, still require a systematic analysis of archival source material detailing actual post-mortem practices for many metropolitan and provincial areas.

Avoiding then post-hoc rationalisation involves carefully examining in context whether in the intervening timespan cultural attitudes to criminal dissections were modified in any respect, and if so, with what outcomes for crime and justice processes from 1752. It is an obvious but important observation to keep in mind that this was a time of considerable intellectual transition as 'scientific' ideas competed with 'Natural Philosophy'. The degree therefore to which the audience at a criminal dissection ever held, or held on to, Northern European sensibilities still needs to be corroborated. Recently, Sarah Tarlow is one of a number 
of historical archaeologists that have reminded historians of crime and justice that beliefs systems about the body in death could be complex and conflicting. ${ }^{19}$ Seemingly incompatible philosophies about the dead body's potency were prolific and determined by local scaffolds of crime and justice. The judicial punishment of the dead, the ceremonial intent of the capital code, as well as the sentience and agency of those present, all ran in parallel. ${ }^{20}$ Alongside a prevalent sense of emotional attachment, elements in the crowd could confound the forces of law and order with indifference. This did not cancel out others obstinacy or reluctance to compromise their cultural beliefs about body-integrity. Yet it did problematize the cultural spread of a spectrum of punishment rites in what was a complicated system of law and order. It contained many types of medicolegal performances involving a wide variety of criminal dissections in those provincial parts of early modern England that still remain understudied. To overcome this lack of coverage, this book's second over-arching theme touches on the official reach of penal powers debated in a history of ideas.

The conventional perspective that the crowd objected to post-execution rites wholeheartedly has served a large theoretical corpus covering crime and punishment, synonymous with the writings of Michel Foucault. ${ }^{21}$ His influence in crime histories has been very extensive indeed; featuring prominently is the disciplinary nature, deterrence value, and legal penalties that involved the crowd, embodiment, and capital sentencing. ${ }^{22}$ The 'historized body' is now seen as a metaphor of power discourses, an historical prism to 'interpret, problematize and destabilize... knowledge/power creation'. ${ }^{23}$ The inherent difficulty nevertheless with the wide-ranging scope of these approaches - whether cultural, literary and/or theoretical-is that they tend to rely on a cartload of notional concepts. Often criminal corpses at the gallows have been piled up in carts laden down with circumstantial evidence. As Roy Porter observed the history of the body has become 'the historiographical dish of the day' and regrettably some scholars have lost sight of the actual physical body being punished. ${ }^{24}$ This book's chapters contend that from a medical standpoint, there has been a strong confirmation bias in crime studies that have effectively mishandled the criminal corpse. Many scholars for instance never think to question whether the criminal was a corpse or a condemned body in deep physical trauma during its prolonged nemesis. It was the case that many criminals did expire on the gallows, but there is equally a lot of contemporary evidence that many others did not perish at the hanging-tree. They did so when they got to their dissection destination. What is needed then is an English local 
history of post-execution rites. The dominance and privileging of certain theoretical approaches has not been as helpful as it could have been in an historical sifting of the evidence on Dissecting the Criminal Corpse.

Few eighteenth-century historians have reappraised what it really meant to physically cut the criminal corpse by dissection. This is because Foucault in Discipline and Punish: The Birth of the Prison (1977 translation) was very critical of 'the purely biological basis of existence' and its empiricism that he believed historical processes had abused in Western society. ${ }^{25}$ The overall thrust of such 'anti-essentialist' thinking has been that researchers have tended to ignore those parts of the capital punishment choreography that are more difficult to access in the archives than others. This explains why nobody has made a serious study of those bodies that were distributed for dissection from the English gallows, in the way that this book does. Hence there has been an overwhelming tendency in eighteenth-century studies to privilege the execution spectacle as an instrument of state power, rather than paying enough historical attention to its equally spectacular postexecution encore across early modern England. This book takes therefore a counter-intuitive approach to the theoretical thrust of cultural studies by stepping back into the archives. The aim of this second strand of research is to arrive at an empirical appreciation of the historical picture of postmortem 'harm' undertaken by penal surgeons post-1752.

The radical uncertainty at the core of the English capital punishment system was that there needed to be an unfinished penal choreography at the hanging-tree. The incomplete punishment journey seemed to give moral authority to the deterrence value of the retribution rites. This medico-legal imperative has stimulated this book's third research strand. Few histories retrace the pace of punishment, its choreography, or medical efficacy. Little is known about what precisely the medical provisos of the legislation entailed, how these were modified over time, and whether they made sense to penal surgeons. What happens again in many standard accounts is that the narrative imperative of the dramatic storyline falls off at the gallows when the body is symbolically dropped. As it figuratively gets released from the rope of the hanging-tree, it falls into a 'cultural compost' of speculative and often unproven sentiments in the historical retelling. ${ }^{26}$ In effect, few studies utilise the contemporary source material to rediscover the missing post-mortem scenery. This status quo is ironic because it did not happen this way in many locations. There was in fact a great deal of sustained interest by contemporaries about what was about to occur at criminal dissections. Many thousands of the labouring poor 
for instance walked with the convicted at arm's length. They viewed the body, watched for life-signs, and stared at the dangerous to make sure they were dead. To enhance its deterrence value the capital code allowed for this level of sustained spectatorship because it was associated with a great deal of physical uncertainty that played on the creative imaginations of those present. Piecemeal steps were created to deliberately confuse the painful processes of punishment and participation on location. ${ }^{27}$ Capital punishment was thus never a simple expression of public engagement. By the post-execution stage it had to be act of co-creation too, to be convincing. This meant that the penal choreography needed to stimulate human empathy, inquisitiveness, meddling, hostility, and insecurity about the painful procedures of post-mortem 'harm' on a body that was supposed to be unfeeling. As a result this book's third generic theme contains a fusion of three open-ended and puzzling punishment pathways: firstly, the impact of the struggle and threat that dissection posed in the popular imagination; secondly, the damage it might potentially cause to those present in terms of their physical capacity for pain and painful spectatorship; and, thirdly, the notoriety and infamy it could create for those condemned to die. There is then much more here than a simple linear story of retribution for murder being enacted and reconstructed in six chapters.

There had to be a punishment paradigm that medico-legal officials could work with, and one that was flexible enough to contain a lot of medical ambiguity: something historians still need to reconstruct in its entirety after 1752 and which this book provides. When looking for instance at the complex nature of the changing audience composition at criminal dissections, we need to be mindful that the political contradictions and moral discrepancies being staged in dissection spaces had subtle, as well as overt, power-balances at play: again something that a lot of cultural studies have yet to substantiate in the archives. Just then as the legal narrative of the punishment drama was not necessarily linear, so too the post-execution spectacle did not always have an undeviating medical logic. This reflected the fact that timings shifted as the choreography of punishment was enacted. Procedures at the gallows looked linear but since they also involved a body operating to a cyclical life-cycle closing down, there was a lot of potential for liminal spaces in the processes of punishment. What seemed to matter most to the sorts of social groups present was that their scaffolds of local justice mirrored popular sentiments and these often reflected curative beliefs about the latent power of the criminal corpse: a theme that Owen Davies and Francesco Matteoni have 
together recently substantiated. ${ }^{28}$ It was obvious to most people involved in the maintenance of law and order, that legal rhetoric and medical realities were neither interchangeable, nor predictable. The majority accepted that different types of criminal dissections would be staged in various medico-legal settings. Punishment criteria had to be imperfect and were inconsistent because these factors, seldom studied until now, matched contemporary expectations. Predictably an assorted number of penal surgeons were assembled who interpreted their medico-legal duties according to parish, county, regional and intra-regional, notions of criminal justice. The material afterlives of criminal corpses tended to reflect popular attitudes to class, gender, and society as well. Physical retribution for murder was seldom fixed and often fluid, with discretionary justice being deliberated and renegotiated, refined and reshaped by changing cultural attitudes to the condemned body in terms of religion, philosophy and science. For contemporaries disposing of the criminal corpse involved 'different projects of inquiry - different spectacles - made different bodies visible in anatomy'and yet crime studies still neglect this medical reality. ${ }^{29}$

England was then covered with deeply symbolic places to dissect the criminal corpse and it is these that all the chapters in some respect will be visiting in considerable archive detail to substantiate a fourth overarching research theme. As well as new source material on the geographical and architectural alignment of chosen dissection spaces in the community, we will also be bringing together familiar sources in novel ways. There will be opportunities to look over the shoulders of attending penal surgeons and to look around the dissection venues they occupied, seeing afresh others present in the room. This included those involved in the secretive side of legal governance which has sometimes hindered the ability of historians to get involved with the sheriffs, their deputies, magistrates, and hangers-on, post-execution. The 'great contrast in their styles of justice compared to the local gentry', and the middling-sort that sat on courtroom juries, meant that once events reached the press the political dance of local retribution became the focus of intense provincial interest. ${ }^{30}$ 'Something of these class and geographical differences emerges' when encountering post-execution crowds on location. ${ }^{31}$ Their attachment to punishment rites as dramatic post-mortem performances in which they were active participants still merits closer historical scrutiny. For crime histories by tending to précis the punishment choreography at the gallows, have not served histories of the crowd well for the early modern period. Instead, a miasma of criminality hangs over the dead-end of convicted murderers when crowds supposedly 
departed at the hanging-tree. Dissecting the Criminal Corpse takes issue with this false finishing-point by relocating different sorts of medico-legal starting-points. This book takes up the end of a storyline that did not stop half-way through and, in research terms, rather than being an end-point should have been a beginning. Early modern society did not abandon or lose interest in the criminal as it was labelled a corpse, quite the reverse. Mingling with post-execution crowds in situ requires historians to retrace stories like those of Half-hanged MacDonald that made medico-legal history, which were lost or inconvenient in the grand punishment narrative of eighteenth-century studies.

Historians of the crowd have tended to be inward-looking for the early modern period. ${ }^{32}$ Recently, Matthew White has taken issue with those in crime studies that 'aggregate' the 'mob' into a 'faceless crowd', prompting a fifth research strand in this book. ${ }^{33} \mathrm{He}$ has rediscovered in early nineteenth-century coroners and Old Bailey records, both an ongoing enthusiasm for execution spectacles and strong emotional attachments to punishment rites that were continually expressed across the social spectrum. His observations that 'depictions of...avid execution-going' have been 'consistently two-dimensional and frequently impressionistic, often paying scant attention to social complexities' have been an intellectual stimulus for the evidence-gathering presented on those that got involved with post-execution rites from $1752 .{ }^{34}$ The crowds at criminal dissections, have, either, been forgotten altogether, or misplaced, and/or constructed as essentially monolithic. Regrettably this has made them a finishingpoint too. Once more, there needs to be a more sinuous starting-point for research on crowds, and one that matches the fluid nature of those that travelled onwards with the condemned, rediscovering their stratified composition in English counties. ${ }^{35}$ Returning to the archives, it becomes feasible to put the personality back into the crowd by accompanying them to dissection venues, thereby building on the approach of Vic Gatrell at the hanging-tree.

In developing this fifth research strand it has been viable to achieve things that have seldom been attempted in standard histories of the postexecution crowd. By concentrating on the historical prism of medical death (our first generic theme) and expanding that to encompass its basic biological continuities which human beings share in all time periods, the chapters are able to reconstruct in some detail the synaesthesia of criminal dissections. ${ }^{36}$ This book is not suggesting that this was a monolithic experience, but it is asserting that there were a range of sensory encounters that 
were unavoidable for everyone in the room at a criminal dissection. It is important to stress (as the most recent research in the medical humanities is doing) that not only did the early modern crowd dress their faces and bodies differently, and follow distinctive fashions to clothe their limbs, but they also 'inhabited bodies that felt different and diverged in shape from ours, dictated by nutritional, health and labour regimes ... From skin and bone, they were nothing like us', as William Pooley points out. ${ }^{37}$ Yet, they did share the same five senses familiar to everyone down the centuries. This means that historians of the body need to rethink what happened when the crowd came to see a criminal corpse that they expected to be both human, and also less than human. The corpse displayed both accessible and 'profoundly unfamiliar flesh'. Historians of crime have tended to understate the contradictory and confusing nature of the experience of viewing criminality exposed. Strong buttocks or limbs, by way of example, on the dissection table were admired in agricultural areas that valued the physical strength of the blacksmith, the drover, and the ploughman. In towns and cities, the clothing and weaving trades promoted the masculine qualities of very strong muscular arms and robust upper body strength. The ways in which the crowd adopted the bare bones of these experiences as flesh separated could then be somewhat disruptive to their bodily sense. The people present had the free will to react but the intellectual and emotional capacity of the crowd was always shaped by sight, smell, hearing, touch, taste, and so on. The undeniable fact was that executed bodies stank, and this was inescapable for those in close proximity. In some respect all those that partook witnessed bleedings, shavings, and slippages in a punishment purge seldom considered in terms of its post-execution spectatorship. Gatrell's work has provided clues about what bodies might have been like on arrival at dissection venues. ${ }^{38} \mathrm{He}$ points out that many executions were bungled. The criminal could be in a 'bloody mess' by the time she/he was cut down from the gallows. It is difficult to understand why then historians of crime and justice have not thought more about the actual condition of the criminal corpse that got handed over to the surgeons. After all, the physical circumstances of execution could have influenced punishment decision-making beyond the gallows too. Encountering bodies in a 'good', 'bad', contaminated', 'dirty', 'diseased' or 'destroyed' condition, as well as rediscovering so-called 'extras', means that the chapters can re-present the 'fleshy' nature of the legal remit in the surgeons' hands. ${ }^{39}$ 
As then the dissection intensified, at a certain physical point in the punishment processes the condemned became repugnant to smell and offensive to look at. It was essential that they did so otherwise the deterrence value of the spectacle was dubious. Yet again, few studies trace the timing of the crowd's agency, and whether it too had a choreography (punishment rites happening to the corpse alongside how the crowd performed their role), and at what point they turned away as the convicted murderer was despoiled for public consumption. Taking the example of how long it took for many thousands to walk past the corpse exposed to public view, as often reported in newspapers at the time, makes it feasible to revisit crowd dynamics. In smaller towns the numbers reported were far greater than the local population census. And as historians of the crowd have pointed out that spectrum of people would have contained very different personal motivations for being there and required sensitive handling by the medico-legal officials charged with ensuring that chaos did not ensue. ${ }^{40}$ The local crowd were insiders and generally curious but benign. Those from the surrounding area could be disruptive as outsiders even though they were generally manageable. Women were often regarded as a litmus test of the ability of the forces of law and order to keep the peace. If they bustled and jostled to view the spectacle, returning up to five times to see the proverbial bad man laid out for inspection in a single day, then there was a very real danger of the 'crowd' becoming a 'mob' that would riot. An added complication was that overlaying those present from the county area, were genuine outsiders, trouble-makers with radical tendencies that often travelled from afar. Sometimes they were the menacing members of the dangerous convict's family. At other times the angry, dispossessed, or unruly came to exploit notoriety by association. This meant that it was essential to get the timing of the post-execution choreography right when up to ten thousand people travelled onwards with the executed body: timing ones departure is a theme elaborated below. It was likewise crucial to entertain, keep the interior dynamics of the crowd moving along, making sure the audience's attention was drawn to different spectacles over several days, and in general, ensuring that post-execution rites had momentum. There was thus a changing profile of medical actors and a strong element of immersive theatre was introduced with people not sitting in seats but walking past the central criminal character. Often there was a timed ticket-entry system too, to better manage audience-flow. When then cultural and criminal histories take the punishment provisions 
of the Murder Act as read, and invariable, they miss so much about the history of the post-execution crowd in terms of its internal drama. Above all, they neglect to appreciate that 'to be hung by the neck until dead, and thence to be dissected and anatomized' was not just a complicated set of medical procedures to orchestrate but they did not tend to work in the way many early modern historians have assumed. As we shall see, the choreography had four stages: social death (being condemned in court), legal death (being hanged), medical death (anatomically checked on arrival at a dissection venue), and only then proceeding to dissection and its material afterlife (post-mortem 'harm'). For now, what is important to keep in mind is that post-mortem procedures in their public performance-and it was much more public than private for most of our chronological focuswere compelling but circumspectly staged, and yet, stimulated significant levels of 'natural curiosity'.

Culminating then in a final generic theme (the book's sixth) all the chapters in some respect explore the emotional capacity of the crowd to appropriate the post-execution rites of the Murder Act. To engage with a history of emotions it is essential to intertwine a definitive sense of eighteenth-century 'curiosity' in the way that Neil Kenny's recent research has done. ${ }^{41}$ Throughout we will be building-up a sense of the 'curious' because for contemporaries it was a multi-layered and mutable set of experiences that often triggered their emotional capacity for awe and revulsion, as well as attraction, fascination, and temptation, and at times, a striking indifference. On the punishment sight-seeing that we are about to embark on across England, there will be opportunities to explore what the differences were between 'natural, 'public', 'morbid' and the worst 'perils of curiosity' at criminal dissections. A paradigm of curiosity has thus been redesigned for this book having traced its historical wallpaper to stimulating archive material. Those sources alert crime studies to reconsider what William Reddy terms 'emotives', which are essentially the emotional expressions that language gives voice to and therefore are very relevant for this study's focus. ${ }^{42}$ 'Emotives' differ from the ability of human beings to describe events because that narrative does not necessarily express how someone feels. The act of speaking about an emotional experience will, according to Reddy, always have the potential to be self-exploring and self-altering. Something intangible can become its opposite when voiced, made literally to be within someone's emotional grasp. A classic example of this in terms of crime and justice was for a member of the crowd to be upset about a vicious murder but to be unable to locate, or express, 
and even suppress, those feelings until at an execution scene. Once the crowd had gathered, the spectacle could be cathartic releasing deep-seated emotions as those present jeered and shouted abuse at the condemned. Throughout the potential existed for emotional tension to be realised, refashioned, re-presented and thus figuratively reached for. All this, could alter the original nature of the experience itself. Once people talked about homicide they sometimes found within themselves an emotional capacity to redefine what they felt and why, in the course of which they rediscovered how to get hold of an emotion at its nucleus. This meant that in the punishment drama, some were more angry, others less so, and the remainder came to a realisation that their anger-level was appropriate for the human situation. This is what is meant by the archaeology of emotions in the crowd that we will be engaging with. ${ }^{43}$ In this book it is argued that Kenny's and Reddy's concepts of 'curiosity' and 'emotives' are very difficult to separate because they were inextricably embedded in the emotional spectrum of the post-execution crowd of early modern England. It was their psychological wherewithal to hold onto a capacity for curiosity in a history of emotions in the transition from a moral to political economy that has framed the way that each chapter has approached those present at criminal dissections. This will add a new dimension to the personality of the post-execution crowd in the same way that synaesthesia can too.

The overall ambition in this book is then to bridge a whole series of liminal spaces inside the criminal justice system-in terms of corporeality, materialism, emotionalism, legalities, mentalities, physical uncertainties and semi-professional identities - that created a dramatic subtext to eighteenth-century criminal life. This backdrop explains why the subject matter of the criminal corpse preoccupied the audiences of many eighteenthcentury playhouses that went on to the dissection theatre too. By 1819 Blackwood's Magazine published a series of popular articles written by theatre critics about these public performances of human anatomy that had grown in popularity since $1700 .{ }^{44}$ In one well-rehearsed dramatic storyline we encounter Time's Magic Lantern and the Dissector (Illustration 1.1):

Doctor: This body is a good subject. It is lean, and therefore well calculated to shew the muscular system. Lay open the abdomen by two transverse incisions, but beware you do not injure the viscera. Now draw aside the outward integuments and you will observe the position of the bowels... I shall demonstrate that in my lecture today. Here, throw up the windows and sprinkle the floor with camphor. Remove the putrid thigh... Cast a sheet over this body and wipe the dissecting instruments with a towel. Now stand behind me and await the entrance... ${ }^{45}$ 


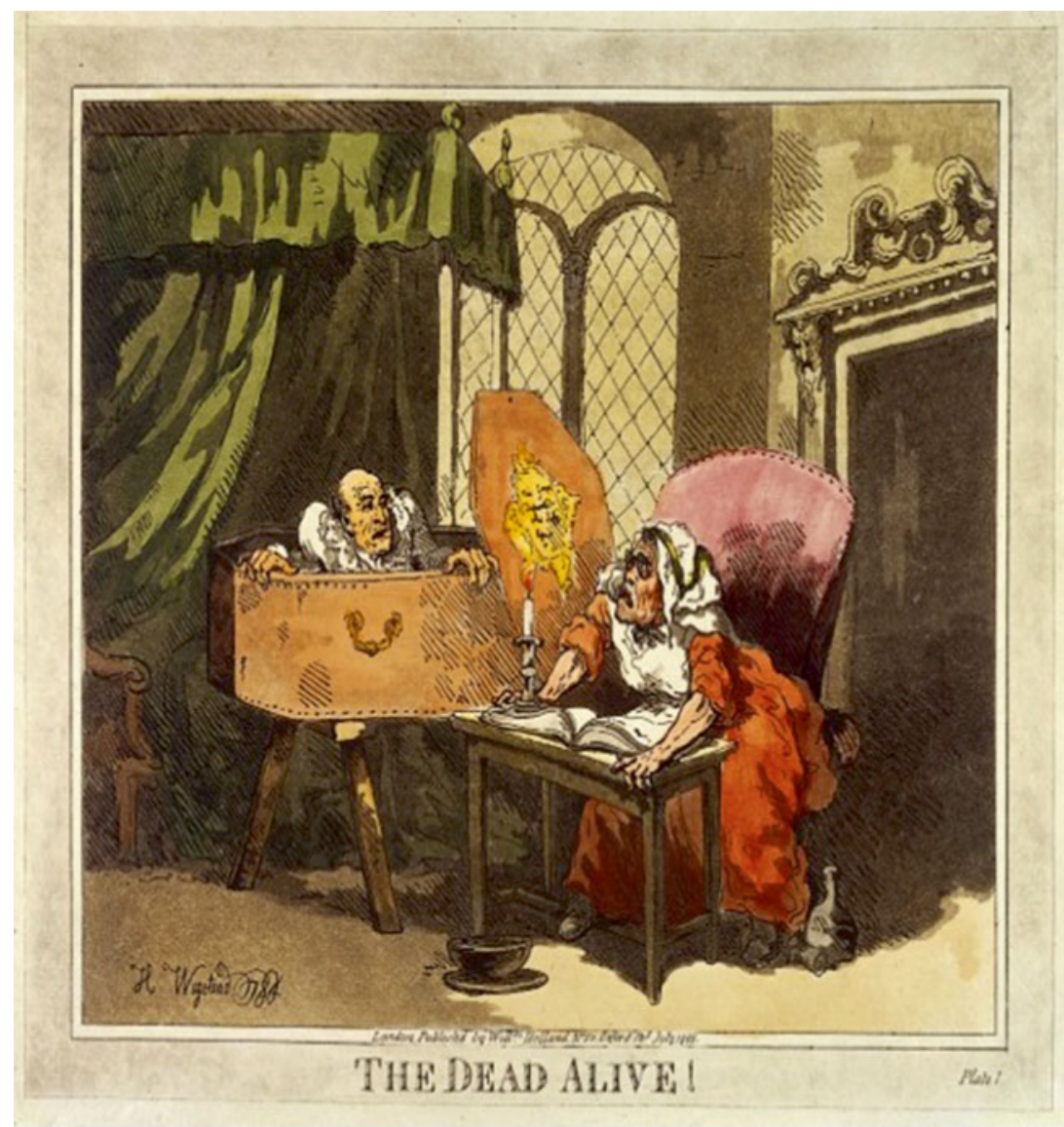

Illustration 1.1 OWellcome Trust Image Collection, Slide Number L0031335, 'The Dead-Alive', illustrating a man supposed to be dead arising from his coffin, coloured aquatint, published 1805, after a 1784 drawing by Henry Wigstead, (London: William Holland, Oxford Street); Creative Commons AttributionNonCommercial-ShareAlike 4.0 International License (CC BY-NC-SA 4.0)

Newspaper reporters often commented on crowds taking an eager part in punishment dramas at the gallows by day and enjoying their theatrical re-enactments at night. There was a grey area between moral edification and grisly entertainment. ${ }^{46}$ Perhaps this explains why historians of the eighteenth-century theatre have rediscovered theatre-goers paying to sit 
on the stage with the actors performing their criminal characters, akin to those that pushed up the spiral staircase at Surgeon's Hall by the Old Bailey having bought a ticket to see the condemned body awaiting dissection. ${ }^{47}$ This desire to get closely involved in deadly dramas meant that contemporaries could accumulate knowledge of post-mortem rituals, becoming sophisticated critics of the criminal justice system being revelled on the stage. The mise-en-scènes was a broader cultural reflection of the extent to which some form of post-mortem punishment of the criminal body and its dramatic timing had become the norm in Georgian England. It is time then to return to the start of what once was a compelling post-execution rite of passage under the Murder Act. In so doing, we are going to take literally what French thinkers should perhaps have paid more attention to when writing about the history of English capital punishment, 'reculer pour mieux sauter' ${ }^{48}$ In a history of the body it is sometimes indispensable to 'step backward in order to leap farther forward'.

\section{Cogi qui POTEST NESCIT MOR $I^{49}: \mathrm{S} / \mathrm{He}$ Who CAN Be Forced, Has Not Learned How To Die}

Once the convicted murderer departed from the courtroom they were in an early modern state of 'social death', according to the Murder Act. They had arrived at this moment of high drama, 'legal death' according to what was once called the Bloody Code covering murder and up to 200 or so capital offences. These broadly-speaking fell into three distinct categories: firstly, petty crime usually associated with the experience of being poor such as stealing food-stuffs and personal chattels for subsistence or to sell on; secondly, property crimes typically house-burglary, highway robbery, as well as sheep-stealing and cattle-rustling; and thirdly, domestic violence or grievous bodily harm leading to manslaughter, and drunken street-brawls culminating ultimately in murder. There were of course many types of homicide charges, with conviction rates, sentencing policies, perpetrator profiles (in terms of age and gender), and socioeconomic causes, being debated extensively by historians of crime and justice for the long eighteenth-century. The focus in this book is those that were convicted of murder, sentenced to death, and then were made available to penal surgeons on the cusp or throes of 'medical death'. These were not capital cases that the judge decided to pardon after the death sentence was passed in court: crime historians concur that about five per cent of those sentenced to capital death were within days subsequently 
shown judicial mercy under the Murder Act. ${ }^{50}$ Any reduction, or indeed cancellation, of the death penalty was generally done once the Assizes was finished but crucially before the judge left town. Typically a lot of pardoning cases resulted in a lesser sentence of 'transported for life' being decreed. This might be as a result of new evidence that came to light once the trial closed. The judge alternatively on reflection might adjudicate that the death sentence was too harsh for an accessory to a felony or did not reflect an unfortunate set of circumstances when an innocent bystander found themselves in court. The majority of judges were always very careful to test the local political temperature on their court circuit. Few wanted to be responsible for a public order situation getting out of control in reaction to a harsh sentencing policy that local people held to be morally objectionable. The pardoning system was however very seldom applied in proven homicide cases. This was a reflection of a sizeable cultural appetite for seeing justice done on the public gallows in cases of murder. The first Biblical commandment, 'thou shall not kill' was morally sacrosanct in early modern Europe. It was linked in the popular imagination to lex talionis - the English common law of retaliation - in which punishment to the criminal body should be seen to match that done to a murder victim. Hence, an eye-for-an-eye mentality got attached to a common definition of pre-meditated murder, inviting judges to punish the criminal corpse by dissection in even the remotest parts of Georgian society. There was though one sentencing option reserved for murderers that committed odious crimes seen as a social evil: these included child murder; causing the mob to riot; threatening the revenue collection of the state in terms say of piracy, smuggling or hijacking the Royal Mail; or lacking personal remorse for a wicked deed like incest or rape in which a victim died and the stability of the family structure was undermined. In such cases, the judge could sentence the convicted murderer to be hung in chains, often called being gibbeted. ${ }^{51}$ Still, for controversial cases, there was a pardoning system, with questions of leniency and discretionary justice being the subject of legal argument and local autonomy. In Georgian times, it was murder most foul that remained high-profile in the dissection theatres of early modern England.

In getting ready to depart from the courtroom it is essential to think graphically about how contemporaries may have broadly viewed what was about to happen, otherwise this book will be walking out of step with the early modern crowd. It is not advisable at this juncture to get lost in hypothetical musings, but some of the broad contours of the historical 
circumstances that have been substantiated do provide a useful guide. Of relevance is that there has been considerable historical dispute about the deterrence value of the punishment rites for homicide and whether the state managed its theatrical role set out in the Murder Act, or not. ${ }^{52}$ At issue is whether the punitive measures and their visceral nature were counter-productive in the end. The balance of the contemporary evidence seems to suggest that ordinary people became either immune to, disinterested by, or critical of, harsh methods of retributive justice as humanitarian ideals gained moral ascendancy by 1800. In parallel however (as we have seen) a common law attitude got enshrined into capital legislation that reflected just how much a deep-seated fear of criminality gained political currency in Georgian times. The mob by virtue of their numeric size had to be accommodated within a more fluid social fabric. Political toleration did not lessen-rather enhanced-a sense of dread on the part of the governing elites and middling-sorts..$^{53}$ Mentalities constrained by such sensitivities - in terms of both rhetoric and reality-in turn shaped medico-legal debates about how to punish the condemned and what physical reprisals to stage in powerful and sometimes disturbing ways. In Georgian England, it was easy to see danger everywhere when political revolution in countries like France by the 1790s had a firm basis in reality. But to protect and preserve the status quo meant there had to a heightened vigilance about more dangerous forms of law-breaking. ${ }^{54}$ This carried with it a real danger that 'any exaggerated publicity could turn out to be corrosive of the sort of security that the ruling parties craved' ${ }^{55}$ To avoid this situation happening, those in power needed to be mindful of a 'circular logic of conspiracy' that might gain a cultural foothold and cause more trouble for officials. This soon proved to be the case in respect of the punishment provisions of the Murder Act, as Part I of this book recounts.

To engage with these complexities it is also necessary to appreciate in broad terms that crime histories have then tended to summarise (usually inaccurately) the medical styles of physical reprisals done to the corpse. This is an incongruous research trend since cutting the murderer symbolically became the subject of so much sustained 'natural curiosity' at criminal dissections over the long eighteenth-century. ${ }^{56}$ Roy Porter and Anita Guerrini have queried the educational purpose of anatomical venues in London: whether they were places of rationale enquiry or staged extra entertainments to attract fee-paying elites. ${ }^{57}$ The balance of the evidence presented in this book suggests that there should be more scepticism about what exactly went on behind the dissection room door in crime 
historiography. ${ }^{58}$ The prevailing viewpoint that 'making justice' was 'often remade from the margins by magistrates, judges and others at the local level', still does not pinpoint with precision the range of formal and informal mechanisms of capital justice delegated to provincial penal surgeons that feature throughout this book. ${ }^{59}$ It is equally important to appreciate the sorts of varied places in which criminal dissections could take place. There was intense local interest by spectators of all social gradations to see the capital sentence taken to its logical conclusion. If excluded (as we shall see in Part II) the crowd did on noteworthy occasions beat down the door to get inside a dissection venue in provincial England. Few were refused admittance because of the very real threat to public order by the mob in decades when making a basic living was hard. ${ }^{60}$ Throughout the chapters thus build on the painstaking research of Andrew Cunningham by setting in context the actual activities of penal surgeons under the Murder Act. ${ }^{61}$ This book takes the framework of his research on the history of anatomy in the eighteenth-century and adds archive detail to it for England. The literature on standards of eighteenth and nineteenth-century medical education is well-covered elsewhere by this author and others, the aim here being to scrutinise the reality of dissecting in places given only a cursory glance. ${ }^{62}$ It will be shown that none of the post-mortem options ineludibly caused 'harm' in the way the capital legislation intended once the condemned departed out of the courtroom.

To start then this symbolic punishment procession, departing to a medico-legal tempo, time and its recurring themes will feature prominently in all the chapters. Time management was one of the implied cornerstones of the Murder Act and yet it has been neglected from a medical standpoint in crime literature. Aspects of it are embedded throughout this book because we are concerned with the biological logistics of the actual medical scene on exiting the courtroom. We will be encountering public clocks ticking down the crucial hour of death on the gallows in market squares. There will be opportunities to engage with penal surgeons checking on a pocket-watch that their criminal body did not go into rigor mortis four hours after being hanged. If it did, then they had to clock-watch until the corpse relaxed enough to manipulate the limbs, generally after twenty-four hours. In winter when colder anatomy sessions slowed down decay the anatomist had to grapple with lower light levels and daytime running out. In summer the heat made the heartbeat race, the hands sweat, and the arm-pits sticky with adrenalin, compelling the 
dissector to quicken their pace, regardless of the anatomical education that was scheduled. Acquiring dexterity with the knife was dependent upon the art of good timing; something echoed in material culture from the time. Clock-makers for instance often decorated their time-pieces with a memento mori to reflect what became known as 'skeleton-time'. ${ }^{63}$

Today it is common for many people to think that the timing of death is something that has always been certain and absolute, a one-way material journey turning from the world of the living. Across European religious traditions a sacred symbolism associated with graveyard customs encouraged individuals to think of death as a 'final moment' that could occur anytime. ${ }^{64}$ So it is understandable that even with the gradual professionalization of medicine such views predominated in the long eighteenthcentury. This book however sees these sorts of general depictions as historically deceptive in terms of actual post-mortem practices. The early modern medical fraternity, 'thought of death as a becoming rather than an ending' - an elementary biology that is often missing from criminal history. ${ }^{65}$ Timing death, in an alternative understanding, involved the recognition that a person 'could die differently according to different chronologies and medico-legal settings', themes explored in Chapters 2 and 3. It was also the case that 'the body-clock could be, for the condemned, wound back; that 'death time' involves the living, the revivified, and the socially resuscitated too': facets of Chapters 4 and 5. Even then for those that did expire on the gallows, their material afterlives and the latent power of criminal corpses pointed to enduring notoriety in death: outcomes depicted in Chapter 6. For this reason two key historical positions inform this book. On the one hand 'the corpse was a locus of all doubt' (as defined by Jonathan Sawday) and on the other hand 'becoming really dead...takes time' (as observed by Thomas Laqueur) from the early modern era onwards. ${ }^{66}$

At each criminal dissection ordinary spectators had just one reliable anatomical perspective, their own body clock. Few carried with them an anatomy textbook or had prior knowledge of what a dissected person really looked like compared to a theatrical re-enactment. Some attended several sessions at Surgeon's Hall in London but tickets were hard to get and the audience were encouraged to leave before extensive dissection (see, Chapter 4). Procedures there were also being modified continuously: a trend that Simon Chaplin first substantiated when he noted how lacklustre anatomical standards were in the capital by the 1790s. ${ }^{67}$ Few historians 
have studied this important insight, as this book does in-depth. It will be shown that the majority of people in provincial life were in many ways better informed than their metropolitan counterparts. Most attended more accessible anatomies: at a surgeon's house, in the open space at the front of Assizes courts, at a room in small medical dispensaries, and inside the dead houses of newly constructed infirmaries (see, Chapter 5). To engage with a criminal afterlife intimately meant therefore taking the time to walk past criminal corpses and visibly comparing them to each spectator's embodied experience. The fact that so many people kept doing so sets in context the compelling nature of getting involved (refer, Chapter 6). A hand might look big, normal or small. The head could be striking, shaved, and misshapen, or non-descript compared to everyone else in the room. Eyes open at death were seen as a sign of guilt and a cultural taboo; so much so that anatomists today recognise that 'lid-watching is a lost medical art' and one that was once very familiar to contemporaries that attended post-execution rites. ${ }^{68}$ It is these shared perspectives that are still accessible despite their historical distance. In this book the body is seen as a reliable form of source material because everyone in all time periods has a basic level of anatomical knowledge about their body and how to keep it going. Rudimentary anatomical labels like-heart, lungs, brain, kidneys, gallbladder, foot, leg, arm, and so on-would have been well-known to the post-execution crowd. It was their colours, shapes, and what they felt like to touch as the body shut down metabolically that required an enquiring mind and accumulated anatomical knowledge. Even though ordinary people present tended not to write down their general observations at criminal dissections, its essential features were so commonplace that historians can engage with their post-mortem attributes. The body has always been its own resource material and talking about it has continuously been emotive; participating without feelings was insupportable. ${ }^{69}$

The next chapters together reconsider what was well-known, what became known, and what remained a medical mystery at criminal dissections. We will encounter the range of official actors-judicial, executive, and medical - that had to manage execution crowds. Source material will be introduced to illustrate how the body itself was once a mutual historical reference point. Knowing how this works was a cornerstone of the Murder Act too and it was what made criminal dissections such a familiar and yet unnerving spectacle. As the body was punished it was physically carried to different locations. The changing medico-legal scenery depended on 
the essential character of criminal justice in the vicinity. Part I therefore provides historical insights into what it meant to dissect. Part II looks at the locations and scope of that dissection work. It will be shown that venues for criminal dissections differed a lot around the country. Four typologies have been identified. These are based on a geographical re-evaluation of dissection venues from detailed regional comparisons. Anatomical methods on location fell into seven generic types and these created material afterlives. Dissecting the Criminal Corpse is hence all about the central medico-legal dilemma of the Murder Act-"mors certa, hora incerta"death is certain, its hour is uncertain. In the complex performance of crime and justice that recurring physical predicament placed a great deal of dramatic licence in the hands of penal surgeons that staffed the Murder Act in 1752 until the Anatomy Act of 1832.

\section{Notes}

1. Moses Aaron Richardson (1843), The Local Historian's Table Book of Remarkable Occurrences Volume II (Newcastle-Upon-Tyne and London: Richardson \& Smith publishers) pp. 44-5.

2. Newcastle General Magazine, September edition, 1754.

3. A full report of this turn of events was eventually published in the Newcastle Courant, 14 October 1754.

4. Local Record of Newcastle, December edition, 1754.

5. The French saying means to 'pick your battles' or 'bide your time and wait for the opportune moment' to reappraise past events; see also, endnote 48 below discussion.

6. Three books admired for this approach in socio-criminal history are penned by the same author: John M. Beattie (1986), Crime and the Courts in England 1660-1800 (Princeton: Princeton University Press); John M. Beattie (2002), Policing and Punishment in London, 1660-1750 (Oxford: Oxford University Press); John M. Beattie (2014 edition), Urban Crime and the Limits of Terror, and The First English Detectives: The Bow Street Runners and the Policing of London, 1750-1840 (Oxford: Oxford University Press).

7. See, J. A. Sharpe (1998 edition), Crime in Early Modern England, 1550-1750 (London: Routledge).

8. Those hung in chains on a gibbet or burned for petty treason feature elsewhere as part of a Wellcome Trust programme grant 'Harnessing the Power of the Criminal Corpse': see http://www2.le.ac.uk/departments/ 
archaeology/research/projects/criminal-bodies-.1 at Leicester University. New findings also feature in, Owen Davies, Elizabeth Hurren and Sarah Tarlow editors of the new series Palgrave Historical Studies in the Criminal Corpse and its Afterlife, in which this new major monograph appears.

9. See, Douglas Hay et al (2011 edition), Albion's Fatal Tree: Crime and Society in Eighteenth-Century England (London: Verso).

10. See, Neville Bonner (1995), Becoming a Physician: Medical Education in Britain, France, Germany and the United States, 1750-1945 (Oxford: Oxford University Press); Ole Peter Grell, Andrew Cunningham and Jon Arrizabalaga eds. (2010), Centres of Medical Excellence? Medical Travel and Education in Europe, 1500-1789 (Surrey: Ashgate).

11. Refer in manuscript copy, BPP, 25 Geo II, c.37, 1752, "An Act for Regulating the Disposal after Execution of the Bodies of Criminals," HL/ $\mathrm{PO} / \mathrm{JO} / 10 / 2 / 61$, Parliamentary Archives.

12. There is a vast amount written on eighteenth-century crime and justice. Selectively, see, V. A. C. Gatrell (1996 edition), The Hanging Tree: Execution and the English People, 1770-1868, (Oxford: Oxford University Press); P. Linebaugh (1996 edition), The London Hanged: Crime and Civil Society in the Eighteenth Century (London: Verso); R. Shoemaker (2004), The London Mob: Violence and Disorder in Eighteenth Century London, (London: Hambledon); Hay et al. (2011), Albion's Fatal Tree; P. J. R. King (2010), Crime and Law in England, 1750-1840: Remaking justice from the margins (Oxford: Oxford University Press).

13. This has been extensive historical debate about whether morality went hand-in-hand with a 'civilising force' in early modern society, causing murder rates to fall and thus creating body-supply problems. See, Norbert Elias (1978), The Civilising Process: The History of Manners (Basel: Urizen Books); Peter Spierenburg (2001), 'Violence and the Civilising Process: Does it Work?' Crime, Histories and Societies, Vol. 5, II, 87-105; Peter Spierenburg (2008), The Spectacle of Suffering: Executions and the Evolution of Repression: From a Pre-Industrial Metropolis to the European Experience (Cambridge: Cambridge University Press).

14. I am very grateful to Steve Poole for sharing with me his latest research on 'Hanging at the Scene of the Crime' given to a Wellcome Trust conference in 2013 at Leicester University \& to be published in R. Ward ed., (2015) A Global History of Execution and the Criminal Corpse (Basingstoke: Palgrave).

15. See, Gatrell, Hanging Tree and Linebaugh, London Hanged.

16. Peter Linebaugh (1975 edition), 'The Tyburn riot against the surgeons' in Douglas Hay, Peter Linebaugh, John G. Rule, E. P. Thompson and Cal 
Winslow eds., Albion's fatal tree: crime and society in eighteenth century England (London: Verso), pp. 65-117.

17. See, notably, Ruth Richardson (2001 edition), Death, Dissection and the Destitute, (London: Phoenix Press); Helen MacDonald (2005), Human Remains: Dissection and its Histories (New Haven: Yale University Press).

18. Jonathan Sawday (1996), The Body Emblazoned: Dissection and the Human Body in Renaissance Culture (New York and London: Routledge), p. 60.

19. Sarah Tarlow (2013), Ritual, Belief and the Dead in Early Modern Britain and Ireland (Cambridge: Cambridge University Press).

20. These themes are embedded in Sarah Tarlow's monograph (cited in endnote 19). I am very grateful to her for sharing with me core ideas that also feature on the publisher's summary of her book's main contribution on the Cambridge University Press catalogue and website.

21. For an excellent summary of the theoretical debates, see, Roger Cooter (2010), 'The Turn of the Body: History and the Politics of the Corporeal', ARBOR Ciencia, Pensamiento y Cultural, CLXXXVI, 743, May-June issue, 393-405.

22. See, Michel Foucault (French edition, 1979) translated to English by Alan Sheridan (1995), Discipline and Punish: The Birth of the Prison (New York: Vintage Books); Colin Jones and Roy Porter eds. (1994), Reassessing Foucault: Power, Medicine, and the Body (London: Routledge).

23. Cooter, 'Turn of the Body', p. 394.

24. Roy Porter (2001), 'History of the Body Reconsidered' in Peter Burke ed., New Perspectives on Historical Writing, (London: Polity Press), pp. 232-260, quote at p. 236.

25. This he clarified in Michel Foucault (1970 edition, English translation), The Order of Things (New York and London: Routledge), preface, p. xvii.

26. I am grateful to Adam Nicolson (2011), The Gentry: Stories of the English (London: Harper Press) for this phrasing in the introduction of his excellent book, pp. ix-xx, which I argue throughout this monograph can be applied to the cultural history of the long eighteenth-century too.

27. See historical debates summarised in, Steven Wilf (1993), 'Imagining Justice: Aesthetics and Public Executions in late eighteenth-century England', Yale Journal of Law and the Humanities, Vol. 5, I, 51-78.

28. I am very grateful for an advance copy of Owen Davies and Francesco Matteoni (2016), Executing Magic: The Power of Criminal Bodies (Basingstoke: Palgrave).

29. Andrew Cunningham (1997), The Anatomical Renaissance: The Resurrection of the Anatomical Project of the Ancients, (Aldershot, Hampshire: Scolar Press), p. 8. 
30. Refer endnote 26 above, for the intellectual debt owed to Nicolson, Gentry here.

31. Ibid., p. 90, the phrasing is Nicolson's but the context in this book is medico-legal.

32. On the conduct of the early modern crowd, see, Nicholas Rogers (1990), 'Crowd and People in the Gordon Riots', in Eckhart Helimuth ed., The Transformation of Political Culture: England and Germany in the late-Eighteenth Century (Oxford: Studies of the German Historical Institute for Oxford University Press), pp. 39-55; John Stevenson (1985), 'The "moral" economy of the English crowd: myth and reality', in Antony Fletcher and John Stevenson eds., Order and Disorder in Early modern England (Cambridge: Cambridge University Press), pp. 218-38; Robert B. Shoemaker (2004), 'Streets of Shame? The Crowd and Public Punishments in London, 1700-1820' in Simon Devereaux and Paul Griffiths eds., Penal Practice and Culture, 1500-1900:Punishing the English (Basingstoke: Palgrave), pp. 232-57; George F. Rudé (2005 edition), The crowd in history: a study of popular disturbances in France and England, 1730-1848 (London: Serif Books); Ian Munro (2005), The figure of the crowd in early modern London: the city and its double (Basingstoke: Palgrave); John Walter (2006), 'Crown and crowd: popular culture and popular protest in early modern England', in John Walter ed., Crowds and Popular Protest in early modern England (Manchester: Manchester University Press), pp. 14-26; Frederick Burwick (2011), Playing to the Crowd: London Popular Theatre, 1780-1830 (Basingstoke: Palgrave).

33. Matthew White (2008), " "Rogues of the Meaner Sort?" Old Bailey Executions and the Crowd in the Early Nineteenth Century', London Journal, Vol. 33, July, II, 135-153.

34. Ibid., p. 148.

35. In a noteworthy aside, Benjamin Heller (2010), "The "Mene Peuple" and the Polite Spectator: The Individual in the Crowd at Eighteenth-Century Fairs', Past and Present, vol. 208, I, 131-157, by focusing on crowds at fairgrounds, points out that early modern historians have often made too many assumptions about their 'heterogeneous nature and appearance' in ways that contemporaries did not conceive of themselves.

36. Recently Mark Forsyth (2013), The Elements of Eloquence: How to Turn the Perfect English Phrase (London: Icon Books), p. 32 has defined 'synaesthesia' as 'either a mental condition whereby colours are perceived as smells, smells as sounds, sounds as tastes and so on, or it is a rhetorical device whereby one sense is described in terms of another'. As we shall see later in this book, both experiences were made feasible by the post-execution 
spectacle. In particular, as Forsyth points out, 'Synaesthesia's of smell are jarring and effective, and are probably an easy shortcut to a memorable line', p. 33. Few forgot a stinking criminal body because it was such a formative experience when first encountered.

37. William Pooley (2014), 'The history of the body in nineteenth-century rural France', Past and Future, Institute of Historical Research Magazine, XVI, Autumn/Winter, p. 17.

38. Refer, Gatrell, Hanging Tree, pp. 29-45, on 'hangings'.

39. In the conclusion to this book we reflect on the new 'fleshy' research of Adam Bencard (2008), 'History in the Flesh', (unpublished PhD, Københavns Universitet. Institut for Folkesundhedsvidenskab. Medicinsk Museion, University of Copenhagen).

40. I am here indebted to two books by John Bohstedt (2010), The Politics of Provisions: Food Riots, Moral Economy, and Market Transition in England, c. 1550-1850 (London: Ashgate) and his (1993), Riots and Community Politics in England and Wales, 1790-1810, (Harvard: Harvard University Press). His thought-provoking chapter, John Bohstedt (1994), 'The Dynamics of Riots: Escalation and Diffusion/Contagion' in M. Potegal and J.F. Knutson eds., The Dynamics of Aggression: Biological and Social Processes in Dyads and Groups (New Jersey: Psychology Press, Lawrence Erlbaum Associate Publishers), pp. 257-306 is equally intellectually-stimulating. His study of food riots and crowd control has in particular inspired a rethinking of criminal dissections and the crowd management issue.

41. Two of his books have been intellectually thought-provoking, Neil Kenny (1998), Curiosity in Early Modern Europe: Word Histories (Wiesbaden: Harrassowitz) and his (2004), The Uses of Curiosity in Early Modern France and Germany (Oxford: Oxford University Press).

42. See, notably, William Reddy (1997), 'Against Constructionism: The Historical Ethnography of Emotions', Current Anthropology, Vol. 38, 327-51. Refer also: William Reddy (1998), 'Emotional Liberty: History and Politics in the Anthropology of Emotions', Cultural Anthropology, Vol. 14, 256-88; William Reddy (2000) 'Sentimentalism and Its Erasure: The Role of Emotions in the Era of the French Revolution', Journal of Modern History, Vol. 72, 109-152; William Reddy (2001), The Navigation of Feeling: A Framework for the History of Emotions (New York: Cambridge University Press); and William Reddy (2009),'Historical Research on the Self and Emotions', Emotion Review, I, 302-315.

43. Building on, Sarah Tarlow (2012), 'The Archaeology of Emotion and Effect', Annual Review of Anthropology, Vol. 41, 169-85. 
44. By way of example, see,, Toni-Lynn O'Shaughnessy (1987-8), “A Single Capacity in The Beggar's Opera”, Eighteenth-Century Studies, Vol. 21, II, Winter, 212-227.

45. Editorial (1819), 'Hiatus, a play of Time's Magic Lantern: No. IX: The Dissector, Blasquez \& Scholar', Blackwood's Magazine, Vol, XXVI, (May) Issue $\mathrm{X}, 161-4$, quote at p. 162.

46. See, below, Illustration 1.1 CWellcome Trust Image Collection, Slide Number L0031335, 'The Dead-Alive', illustrating a man supposed to be dead arising from his coffin, coloured aquatint, published 1805 , after a 1784 drawing by Henry Wigstead, (London: William Holland, Oxford Street); creative commons license authorised for academic purposes.

47. This finding was highlighted at a recent exhibition of eighteenth-century plays at the Victorian and Albert Museum: http://www.vam.ac.uk/ content/articles/0-9/18th-century-theatre/.

48. It is used figuratively to mean 'pick your battles' or 'bide your time and wait for the opportune moment': both literal and figurative apply to the Murder Act in England.

49. The legal early modern Latin translation is cited here in common English.

50. I am grateful here to Peter King for clarifying this context in conversations with the author. See, also, Gatrell, Hanging Tree, pp. 566-89.

51. I am grateful for an advance copy of Sarah Tarlow (2016), Hanging in Chains: Gibbeting and the Murder Act (Basingstoke: Palgrave Pivot). For that reason this feature of post-mortem 'harm' is not covered in this book.

52. Refer, again, Wilf, 'Imagining Justice', pp. 51-78.

53. See, notably, Thomas Laqueur (1989), "Crowds, Carnival, and the State in English Executions, 1604-1868," in A.L. Beier, David Cannadine, and James Rosenheim eds., The First Modern Society: Essays in English History in Honour of Lawrence Stone (Cambridge: Cambridge University Press), pp. 305-56. Also: John Brewer (1979-80), 'Theatre and Counter-Theatre in Georgian Politics', Radical History Review, Vol. 32, 7-40; and Terry Castle (1986), Masquerade and Civilization: The Carnivalesque in Eighteenth-Century English Culture and Fiction (London and Stanford: Stanford University Press), pp. 1-51.

54. Highlighted, by, Nicolson, The Gentry $\rightarrow$ see also, endnotes 26 and 30.

55. Ibid., points out that this siege mentality was often at the heart of the property-owning divisions in England; Nicolson describes gentry magistrates and their jurymen from the sixteenth century as being open to newcomers but essentially acting as a 'government bordering on tyranny, in a country filled with sweet musk roses and eglantine', p. 43.

56. On the main theoretical approaches in medical history, see, Roy Porter (2003), Flesh in the Age of Reason: How the Enlightenment Transformed the Way We See Our Souls and Bodies (London: W. W. Norton and Co). 
57. A. Guerriini (2004), 'Anatomists and Entrepreneurs in Early Eighteenth Century London', Journal of the History of Medicine and Allied Sciences, Vol. 59, April, II, 219-39; Roy Porter (1988), 'Seeing the Past', Past and Present, Vol. 118,186-203.

58. See, for example, Randy McGowan (2003)'The Problem of Punishment in Eighteenth-Century England' in Simon Devereux and Paul Griffiths eds., Penal Practice and Culture, 1500-1900: Punishing the English, (Basingstoke: Palgrave), pp. 210-31; Randy McGowan (2005), 'Making Examples' and the Crisis of Punishment in Mid-Eighteenth-Century England' in David Lemmings ed., The British and Their Laws in the Eighteenth Century, (Woodbridge: Boydell), pp. 182-205 in which dissection is seen as less high-profile than gibbeting, and the privilege of a medical elite: viewpoints this book takes issue with and returns to in Chapter 7.

59. This book therefore builds on Peter King's admirable work in Crime and Law in England, endnote 12.

60. There is often a strong historical emphasis on the primacy of a stable political economy at the time; see, by way of example, two useful books by James A. Sharp (1990), Judicial Punishment in England (London: Faber and Faber) and his (1998 2nd edition) Crime in Early Modern England 1550-1750 (London: Longman).

61. Andrew Cunningham (2010), The Anatomy Anatomis'd: An Experimental Discipline in Enlightenment Europe (Aldershot, Hampshire; Ashgate).

62. Notably, E. T. Hurren (2011 edition), Dying for Victorian Medicine: English Anatomy and its Trade in the Dead Poor, 1832 to 1929, (Basingstoke: Palgrave), chapter 3. Important context can also be found in, Susan Lawrence (2002), Charitable Knowledge: Hospital Practitioners and Pupils in Eighteenth Century London (Cambridge: Cambridge University Press); Keir Waddington (2003), Medical Education at St. Bartholomew's Hospital, 1123-1995 (Woodbridge: Boydell); Jonathan Reinarz (2009), Healthcare in Birmingham: The Birmingham Teaching Hospitals, 1779-1939 (Woodbridge: Boydell).

63. See, for example, Wellcome Library Collection, Wellcome Images, V0042183, 'A Clock Dial on which a Skeleton holds an Oil Lamp, drawn by Caleb Elwin', reproduced in Cambridge, 1800.

64. Simon Marsden (2007), Memento Mori: Churches and Churchyards of England (London: English Heritage).

65. I am very grateful to Dr. Shane McCorrestine for these stimulating ideas which form the central focus of a conference he convened on 'When is Death' at Leicester University in April 2015, and whose findings will feature in an edited volume by Palgrave in 2016. 
66. Sawday, Body Emblazoned, p. 88 and Thomas Laqueur (2011), 'The Deep Time of the Dead', Social Research, Vol. 78, Fall, III, 799-820, quote at p. 802.

67. Simon Chaplin (2009), 'John Hunter and the Museum Oeconomy, 1750-1800', (unpublished $\mathrm{PhD}$, King's College London).

68. A. D. Macleod (2009), 'Eyelid Closure at Death', Indian Journal of Palliative Care, Vol. 15, July-December, II, 108-110, quote at p. 108; Hippocrates wrote about eyes open versus eyes closed, and its cultural taboos, noting that the lower lids often remain open in brain trauma-an observation still made about fatal neurological conditions and at executions by lethal injection in America today.

69. Reddy, 'Against Constructionism: The Historical Ethnography of Emotions'. permits use, duplication, adaptation, distribution and reproduction in any medium or format, as long as you give appropriate credit to the original author(s) and the source, provide a link to the Creative Commons license and indicate if changes were made.

The images or other third party material in this book are included in the work's Creative Commons license, unless indicated otherwise in the credit line; if such material is not included in the work's Creative Commons license and the respective action is not permitted by statutory regulation, users will need to obtain permission from the license holder to duplicate, adapt or reproduce the material. 